\title{
Upgrading of textile manufacturing based on Industry 4.0
}

\author{
Zhen Chen ${ }^{1,}$, Mingjie Xing ${ }^{1, b^{*}}$ \\ ${ }^{1}$ College of Textile, Qingdao University, Qingdao, Shandong 266071, China \\ acz116688@163.com, bxmjqdu@126.com \\ * corresponding author. e-mail: xmjqdu@126.com
}

Keywords: textile industrial upgrading; Industry 4.0; intelligent manufacturing; CPS; IoT.

Abstract. China textile competitive edge fades as the increase of production factors cost. "Industry 4.0" solution would boost industrial upgrading to realize intelligent and flexible manufacturing for mass customization. Cyber-physic system (CPS) and Internet of things (IoT) are essential for the future manufacturing. This paper provides illustrative examples and presents the principle of the textile collaboration network. It discusses the obstacle of industrial upgrading and offers proposals on implementation policies.

\section{Introduction}

Due to the rising cost, high-end consumer, and the complex value chain, competitiveness of China's manufacturing industry weakens. Besides, re-industrialization sweeps the world, which makes it imminent to upgrade [1]. Based on the manufacturing PMI index, RCA competition index and textile cost analysis, this work shows the current situation of China's textile manufacturing industry and provides a reference for enterprises.

China textile production slows down and export growth picks up. PMI (Revealed Comparative Advantage) index (Fig. 1) indicates a depression of China's manufacturing. BCG (Boston Consulting Group) releases a report [2] presenting that China cost advantage is considerably diminished.

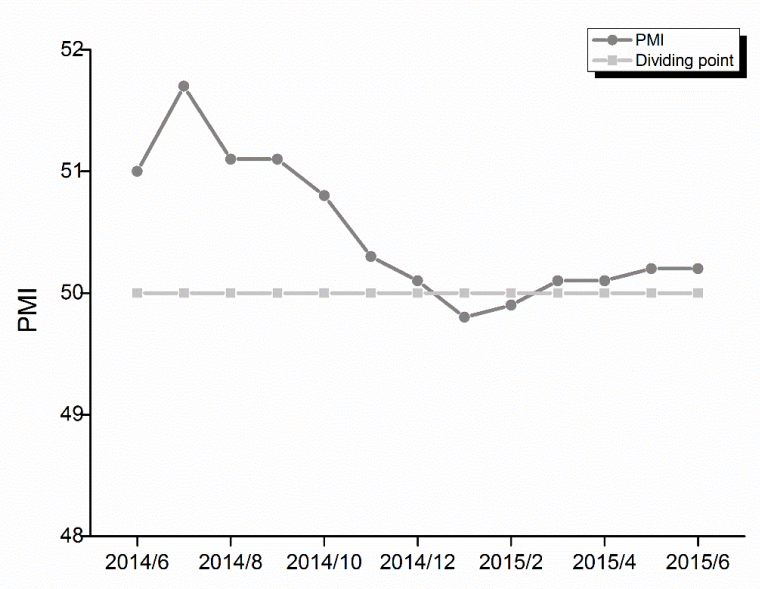

Fig. 1 Graph of China PMI

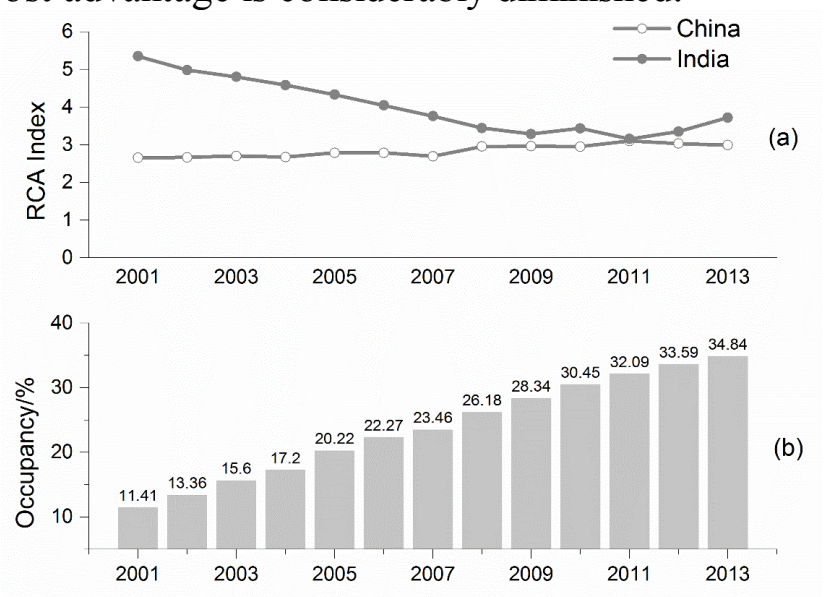

Fig.2 (a) RCA index of China and India;

(b) China textile exports share

According to a RCA (Revealed Comparative Advantage) index and export share (Fig. 2) based on WTO data [3], China export performs a high occupancy, but India has a higher RCA index. International Textile Manufacturers Federation released 2014 International Production Cost Comparison Report [4], as is shown in Fig. 3 that illustrates a poor total cost advantage in China. 

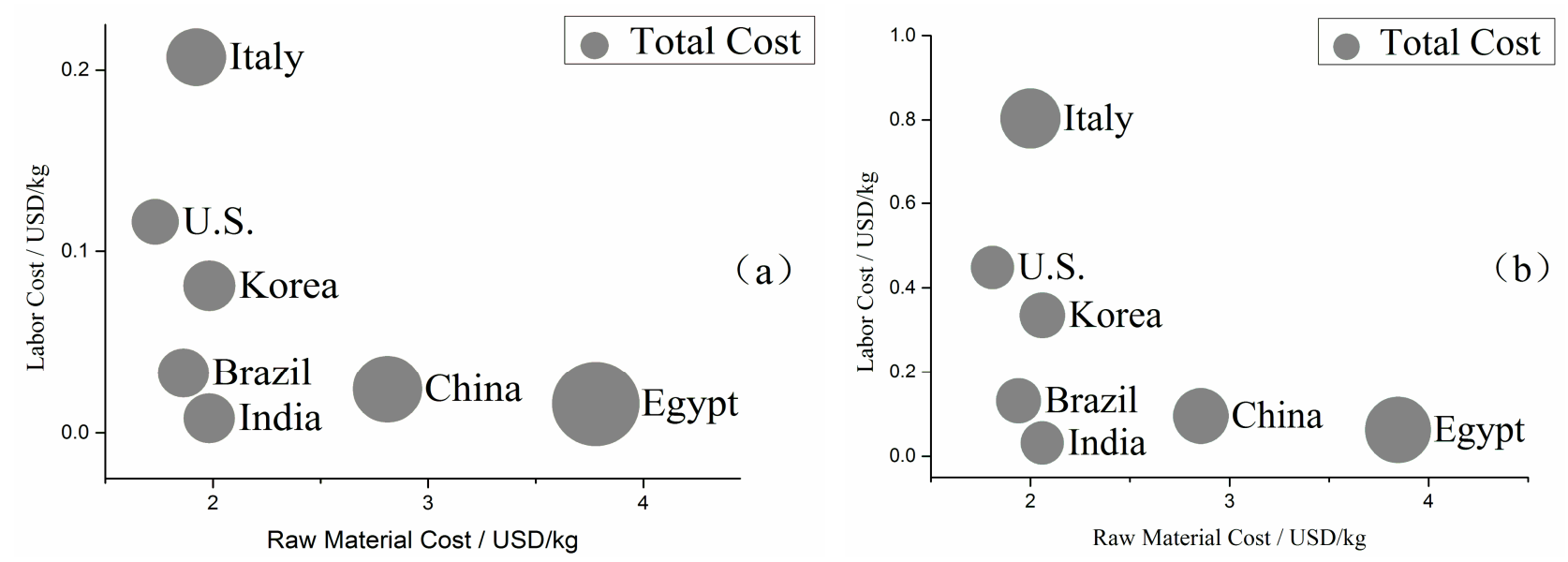

Fig. 3 Labor, raw material and the total cost of yarn production comparison:

(a) Rotor yarn; (b) Ring yarn.

\section{Textile Intelligent Manufacturing}

\section{Intelligent Manufacturing}

In 1991, Mark Weiser proposed the concept of pervasive computing [5] that computing and communications devices will be embedded anywhere and implement information exchange. George Stylios [6] assumed that the key to change textile production fundamentally was intelligent computing and engineering environment, production process integration and manufacturing flexibility.

Intelligent Manufacturing is an application of network information technology throughout the manufacturing supply chain and characterized by consumer demand-led and collaborative development. Smart factory provides a flexible, adaptive solution for intelligent manufacturing [7].

\section{Industry 4.0.}

2011 Hanover Messe put forward the "Industry 4.0" concept for the first time and "Industry 4.0" roadmap was released in 2013. It is characterized [8]:Horizontal integration across value networks, end-to-end digital integration across the entire value chain and vertical integration and networked production systems. Industry 4.0 will lead to virtualization and modularization of production process and supply chain, achieving flexibility and personalization of production [9] based on CPS and IoT together with ERP, MES, PLM, SCM and other software system.

CPS can monitor the production process and realize decentralized decision-making and self-optimize. Real-time communication between machine and machine (M2M) or human could be implemented through IoT and CPS [10]. Information is shared across the entire collaborative network. From raw materials to product sales, digital tracking device is connected to each other according to standard protocols for data analysis, errors forecast and self-configuring.

\section{Textile 4.0}

Key technologies of automation in spinning, weaving and other aspects are essential to upgrade the textile industry. Textile 4.0 would be a process chain of independent production [11] (Fig. 4). Information carrier can be textile material container, bobbin, warp beam, and fabric. Radio frequency identification technology (RFID) [12] and sensors are basic to collect and store information, such as equipment operation status, and maintenance information. The plant will self-configure and self-optimize [13] (Fig. 5) quickly and flexibly to meet custom manufacturing orders. Meanwhile, all information will be fed back to the MES and ERP systems for future management decisions. 


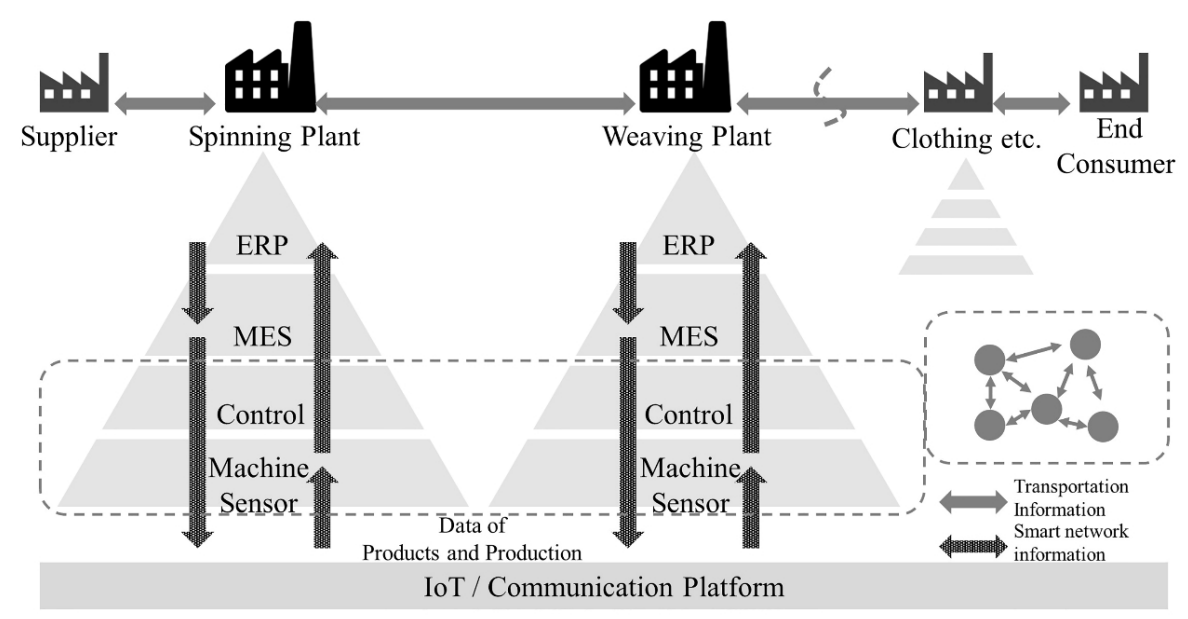

Fig. 4 Schematic diagram of information transformation in textile 4.0

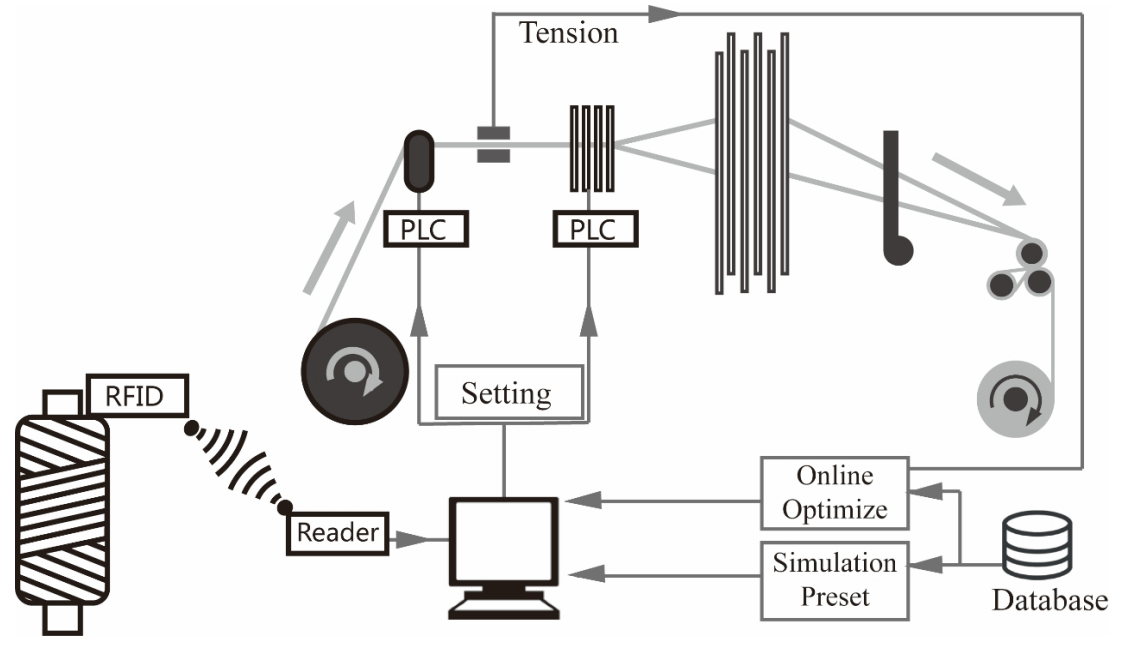

Fig. 5 Self-optimizing of weaving process

Future maintenance would be more timely and efficient. MES system storages and displays device operational information, equipment depreciation and maintenance schedules and monitoring system would transmit information to the machine manufacturer and get a 3D model and repair guide, or call for remote maintenance from provider (Fig. 6).

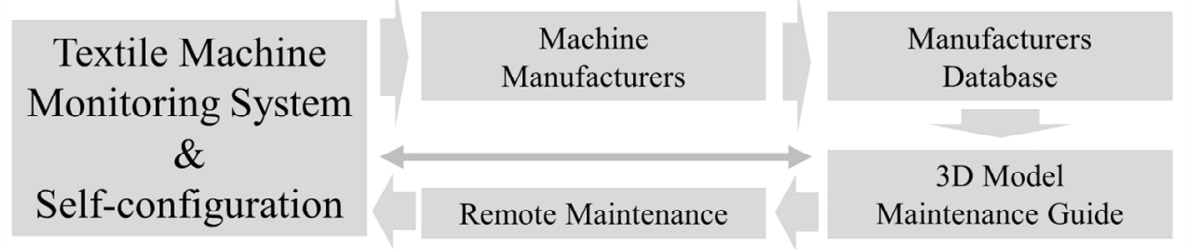

Fig. 6 Schematic diagram of machine maintenance in smart manufacturing

\section{Opportunities and Challenges}

The next stage of development is an era of integration of traditional manufacturing industries and smart technology. It is imperative to promote the development of key technologies of intelligent manufacturing and strengthen skilled personnel training. Establishing pilot and spreading experience is a promising way, as well as homogenization competition alliance (HCA), especially for small and medium-sized enterprise.

Since Industry 4.0 is in its initial phase, it is unadvisable to pursue it blindly and exaggerate its significance for the manufacturing industry. Most textile manufacturing, lacking innovation, is at 
mid-low end of the value chain. It is feasible to consider synthetically both the new upgrading and the basic construction. Several issues must be resolved, such as setting and implementation of the industry standard, device protocol and information sharing scheme.

\section{Conclusions}

The boom of global "re-industrialization" would make manufacturing more intensely competitive and the traditional model is substituted for emerging model, which could be called integration of industrial chain better than an industrial revolution, and all participants in the production process collaborate production in a new way. Textile industry must be aware of the new challenges and respond with a judicious action in order to reduce production cost, improve manufacturing productivity, promote industrial growth, change the labor force structure and ultimately change the competitiveness of the company and the region. Technological innovation and personnel are basic drive of industry transformation. Meanwhile, it should be cautious to upgrade textiles 4.0 and it is imminent to figure out the industry standard and its implementation.

\section{References}

[1] Mu Y. Challenge and Strategy of China's Textile Industry[J]. Cotton Textile Technology, 2014, 42(2): 1-4. (in Chinese)

[2] Sirkin H L, Zinser M, Rose J R. The shifting economics of global manufacturing[R]. BCG, 2014.

[3] Information on http://stat.wto.org/Home/WSDBHome.aspx.

[4] ITMF. International Production Cost Comparison: Spinning / Texturing / Weaving / Knitting[R]. 2014.

[5] Weiser M. The computer for the 21st century[J]. Scientific american, 1991, 265(3): 94-104.

[6] Stylios G. The principles of intelligent textile and garment manufacturing systems[J]. Assembly Automation, 1996, 16(3): 40-44.

[7] Zuehlke D. SmartFactory-Towards a factory-of-things[J]. Annual Reviews in Control, 2010, 34(1): 129-138.

[8] Chun D, Junyang L. Germany "Industry 4.0": Content, Motive, Prospects and Its Implications and Prospects[J]. Germany-studies, 2014, (4). (in Chinese)

[9] Brettel M, Friederichsen N, Keller M, et al. How virtualization, decentralization and network building change the manufacturing landscape: An Industry 4.0 Perspective[J]. International Journal of Science, Engineering and Technology 8 (1), 37, 2014, 44.

[10] Hermann M, Pentek T, Otto B. Design Principles for Industrie 4.0 Scenarios: A Literature Review[J], 2015.

[11] Saggiomo M, Wischnowski M, Winkel B, et al. Industry 4.0 in the field of textile machinery-first steps of implementation[J]. Melliand International, 2015, (1).

[12] Hameed B, Durr F, Rothermel K. RFID based Complex Event Processing in a Smart Real-Time Factory[J]. Expert discussion: Distributed Systems in Smart Spaces, 2011.

[13] Gloy Y S, Sandjaja F, Gries T. Model based self-optimization of the weaving process[J]. Cirp Journal of Manufacturing Science \& Technology, 2015, 9: 88-96. 